\title{
Kaji Eksperimen Angka Asam dan Viskositas Biodiesel Berbahan Baku Minyak Kelapa Sawit dari PT Smart Tbk.
}

\section{Experiment Study Of Total Acid Number And Viscosity Of Palm Oil Based Biodiesel From PT Smart Tbk}

\author{
Lia Laila \\ Institut Teknologi dan Sains Bandung \\ Program Studi Teknologi Pengolahan Sawit \\ Bekasi, Indonesia \\ lia.laila131@gmail.com
}

\author{
Listiana Oktavia \\ Institut Teknologi dan Sains Bandung \\ Program Studi Teknologi Pengolahan Sawit \\ Bekasi, Indonesia \\ oktavialisti@gmail.com
}

\begin{abstract}
Abstrak - PT Smart Tbk merupakan perusahaan yang mempunyai luas lahan kelapa sawit terbesar di Indonesia. Minyak kelapa sawit atau CPO (Crude Palm Oil) hasil produksi PT Smart Tbk sangat berpotensi untuk menyuplai bahan baku biodiesel. Beberapa parameter yang sangat berpengaruh pada kualiatas biodiesel adalah nilai angka asam (TAN-Total Acid Number) dan viskositas. Nilai angka asam dan viskositas yang tidak sesuai standar dapat menurunkan kinerja mesin. Pada penelitian ini, nilai yang diukur adalah biodiesel murni, solar, dan biodiesel campuran hasil blending dengan solar. Pembuatan biodiesel dari CPO dilakukan dengan menggunakan reaksi transesterifikasi dengan katalis basa. Standar pengujian untuk angka asam mengikuti standar pengujian yang telah teruji berdasarkan aturan dari forum biodiesel Indonesia, sedangkan pengukuran viskositas dilakukan pada temperatur $40^{\circ} \mathrm{C}$ (sesuai standar SNI viskositas biodiesel) menggunakan viscometer Ostwald. Nilai angka asam dan viskositas pada SNI maks $0,5 \mathrm{mg}$ $\mathrm{KOH} / \mathrm{g}$ sampel dan $2,3-6,0 \mathrm{~mm}^{2} / \mathrm{s}(\mathrm{cSt})$. Nilai angka asam dan viskositas hasil penelitian berkisar antara 0,202-0,531 mg-KOH/g dan 3,62 - 4,35 $\mathrm{mm}^{2} / \mathrm{s}$ (cSt). Ditinjau dari nilai angka asam dan viskositas tersebut, biodiesel berbahan baku CPO dari PT Smart Tbk memenuhi SNI dan dapat direkomendasikan sebagai bahan baku biodiesel nasional. Sehingga diharapkan penggunaan biodiesel dapat terlaksana secara terus menerus dan berkelanjutan sebagai sumber energi pengganti fosil di Indonesia.
\end{abstract}

Kata Kunci-biodiesel; TAN; viskositas; PT Smart Tbk; CPO

Abstract - PT SMART Tbk is the largest palm oil plantation company in indonesia. Crude Palm Oil (CPO) produced by PT SMart Tbk has big potential as a raw material for biodiesel production. The quality of palm oil-based biodiesel can be reviewed from some parameters, such as : Total Acid Number (TAN) and Viscosity value. TAN and kinematic Viscosity value which don't meet the standard can deteriorate the performance of engine. In this study, we would like to analyse TAN and kinematic Viscosity value of biodiesel produced from CPO. Moreover in this research, we would like to investigate TAN and kinematic viscosity of blend liquid of biodiesel and comercially available fosil fuel (solar) to see how can blending process effects both parameters TAN and kinematic viscoity of biodiesel. The production of biodiesel is based on trans-esterification reaction between $C P O$ and methanol using base catalyst. Measurement standard for TAN refers to Forum Biodiesel Indonesia standardand kinematic viscosity value is investigated at $40^{\circ} \mathrm{C}$ using Ostwald viscometer. The maximum of TAN number set by SNI is $0.5 \mathrm{mg} \mathrm{KOH/gram} \mathrm{sample} \mathrm{and} \mathrm{kinematic}$ viscosuty must be in the range $2.3-6,0 \mathrm{~mm}^{2} / \mathrm{s}$ (cST). In this research, TAN number of sample lies in the range of 0.202-0.531 mg-KOH/gram sample and kinematic viscosity is recorded between 3.62-4.35 $\mathrm{mm}^{2} / \mathrm{s}(\mathrm{cST})$. Based on TAN and kinematic viscosity number, produced biodiesel and bleding samples are recommended for national biodiesel fuel resource. In the next, utilization of biodiesel hopefully will be executed continiouslly to reduce our dependency over fossil fuel.

Keywords — biodiesel, TAN, viscosity, PT Smart Tbk, CPO

\section{PENDAHULUAN}

Bahan bakar nabati dapat dimanfaatkan untuk memenuhi kebutuhan energi sebagai pengganti fosil. Salah satu bahan bakar nabati yang dapat digunakan untuk penganti solar adalah biodiesel. Minyak kelapa sawit berpotensi besar untuk dijadikan bahan baku pembuatan biodiesel karena mempunyai rendemen sebanyak $28 \%$. Indonesia sebagai produsen terbesar minyak kelapa sawit atau CPO (Crude Palm Oil) di dunia mempunyai visi mewujudkan Indonesia menggunakan sumber energi baru terbarukan (pengganti fosil) sebanyak $25 \%$ pada tahun 2025 dalam rangka konservasi energi dan diversivikasi energi [1]. Salah satu program pemerintah pada tahun 2016 yaitu pencanangan penggunaan B20 (pengganti solar dengan komposisi $20 \%$ biodiesel dan $80 \%$ solar). PT Smart Tbk sebagai perusahaan dengan luas lahan kelapa sawit terbesar di Indonesia sangat berpotensi untuk menyuplai bahan baku biodiesel. Parameter yang sangat berpengaruh dalam penggunaan biodiesel diantaranya adalah angka asam dan viskositas. Nilai SNI biodiesel angka asam tidak boleh melebihi $0,5 \mathrm{mg}-\mathrm{KOH} / \mathrm{g}$ dan viskositas kinematik (pada $40^{\circ} \mathrm{C}$ ) berkisar antara 2,3-6,0 $\mathrm{mm}^{2} / \mathrm{s}$ [2].Nilai angka asam dan viskositas yang terlalu tinggi dapat merusak performa mesin. 
Sehingga perlu dikaji angka asam dan viskositas biodiesel berbahan baku minyak kelapa sawit dari PT.Smart Tbk.

Dalam penelitian ini dilakukan proses konversi dari trigliserida (CPO) menjadi metil ester melalui reaksi transesterifikasi dengan menggunakan katalis basa. Baik asam maupun basa, dapat digunakan sebagai katalis, namun laju pembentukan metil ester mengggunakan katalis asam adalah rendah jika dibandingkan dengan katalis basa[3]. Syarat suatu bahan bisa digunakan sebagai bahan baku untuk biodiesel adalah bahan tersebut memiliki komposisi trigliserida ditas 95\% serta memiliki kandungan FFA (Free Fatty Acid) atau asam lemak bebas dibawah $2 \%$ [4]. Jika suatu sampel minyak yang mengandung FFA diatas $2 \%$ maka harus dilakukan proses pre-treatment terlebih dahulu yaitu reaksi esterifikasi dari FFA menjadi metil ester.

\section{BAHAN DAN METODE}

Bahan: CPO (Crude Palm Oil) berasal dari PT Smart Tbk dan langsung digunakan tanpa ada perlakuan tambahan, $\mathrm{KOH}$ (p.a.), Metanol (99\%), larutan Fenoftalen, Etanol 96\%, $\mathrm{H}_{2} \mathrm{SO}_{4}$ 98\%, Asam asetat $\left(\mathrm{CH}_{3} \mathrm{COOH}\right) 0.1 \mathrm{M}$, Kalium Hidroksida $(\mathrm{KOH})$ alkoholik (etanol) $0.1 \mathrm{~N}$, Kloroform $\left(\mathrm{CHCl}_{3}\right)$, Solar (Pertamina), Asam klorida $(\mathrm{HCl})$, Asam periodat $\left(\mathrm{HIO}_{4} .2 \mathrm{H}_{2} \mathrm{O}\right)$ p.a., Natrium tiosulfat $\left(\mathrm{Na}_{2} \mathrm{~S}_{2} \mathrm{O}_{3} .5 \mathrm{H}_{2} \mathrm{O}\right)$ p.a.

Metode: Penelitian ini dibagi menjadi dua tahap besar : (1) Pembuatan biodiesel dari CPO PT SmartTbk. (2) Analisis beberapa karakter fisik dan kimia dari sampel biodiesel yang dihasilkan serta sampel hasil pencampuran dengan solar. Karakter fisika yang diuji meliputi uji viskositas pada $40^{\circ} \mathrm{C}$ sedangkan uji sifat kimia meliputi uji angka asam, uji kadar metil ester, uji kadar gliserol total serta uji angka penyabunan.

\section{A. Pembuatan Biodiesel dari $C P O$}

Proses konversi CPO atau Crude Palm Oil menjadi biodiesel (metil ester) dilakukan dengan menggunakan reaksi trans-esterifikasi dengan katalis basa[3]. Sebelum proses transesterifikasi, perlakuan pendahuluan perlu dilakukan kepada bahan mentah CPO. Tindakan pendahuluan yang dimaksud adalah melakukan reaksi esterifikasi pada CPO yang akan ditransesterfikasi. Esterifikasi pada CPO dimaksudkan untuk menurunkan kadar FFA dalam bahan baku CPO. FFA yang terlalu tinggi ( $>2 \%$ ) pada bahan baku mengakibatkan kecilnya kadar metil ester yang dihasilkan.

Proses pembuatan biodiesel dari CPO ditunjukkan dengan diagram alir pada Gambar 1.

Identifikasi awal dari CPO yang berasal dari PT SmartTbk menunjukan nilai FFA berada diatas 5\%, hal tersebut mengakibatkan perlu adanya proses pre-treatment pada bahan baku CPO yang akan di-esterifikasi. Sebagaimana ditunjukan pada Gambar 1, apabila FFA CPO berada diatas 2\%, maka CPO tersebut harus di-esterifikasi dengan menggunakan metanol dan katalis asam. Katalis asam yang digunakan hanya $1 \%$ serta ratio mol CPO : metanol adalah 1:14.

Proses transesterifikasi menggunakan katalis basa yaitu dengan $\mathrm{KOH}$ komposisi $2 \%$ w/w terhadap masa CPO. Rasio mol CPO : Metanol yang digunakan adalah 1 : 6. Proses transesterifikasi dilakukan dengan metode reflux untuk menghindari kehilangan pelarut selama proses reaksi.

Hasil trans-esterifikasi dimurnikan dengan cara dicuci menggunakan air hangat $\left(50-60^{\circ} \mathrm{C}\right)$ sampai $\mathrm{pH}$ air cucian menjadi netral. Untuk meminimalisir pembentukan sabun saat pencucian dengan air hangat, larutan asam asetat $\left(\mathrm{CH}_{3} \mathrm{COOH}\right)$ $0.1 \mathrm{M}$ ditambahkan pada hasil reaksi sebelum dicuci dengan air hangat. Hasil pencucian dengan air dilakukan dengan teknik dekantasi menggunakan corong pisah. Biodiesel yang dihasilkan kemudian dikeringkan dengan teknik destilasi vakum untuk menguapkan air yang terperangkap dalam biodiesel pada fasa atas.

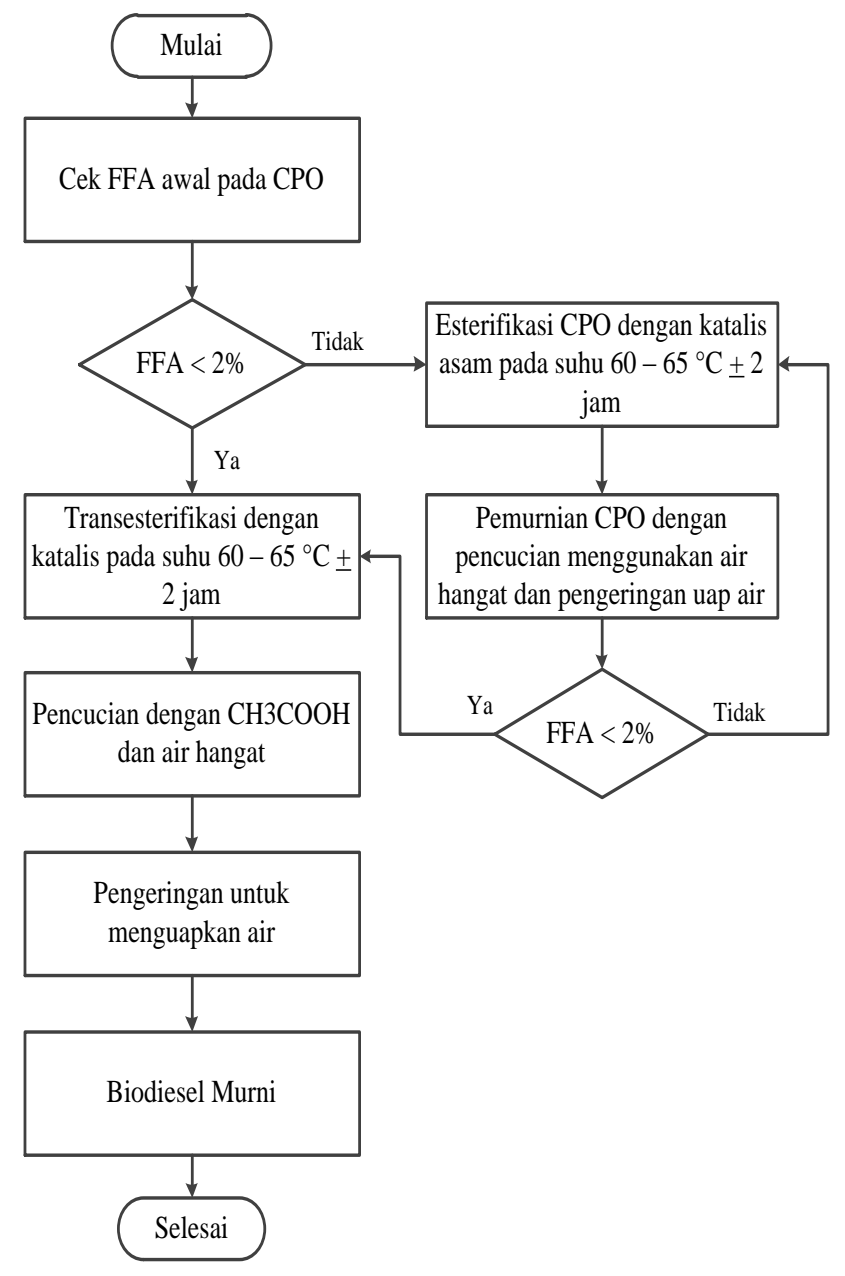

Gambar 1. Diagram Alir Pembuatan Biodiesel dari CPO

\section{B. Pencampuran Biodisel dan Solar}

Sifat fisik dan kimia sampel yang diuji yaitu solar murni, biodiesel murni, dan campuran biodiesel-solar dengan berbagai proporsi tertentu sebagaimana ditunjukkan dalam Tabel I. 
TABEL I. KOMPOSISI BIODIESEL - SOLAR

\begin{tabular}{|c|c|c|}
\hline \multirow{2}{*}{$\begin{array}{c}\text { Nama } \\
\text { sample }\end{array}$} & \multicolumn{2}{|c|}{ Komposisi } \\
\cline { 2 - 3 } & Solar (\%) & Biodiesel (\%) \\
\hline B0 & 100 & 0 \\
\hline B10 & 90 & 10 \\
\hline B20 & 80 & 20 \\
\hline B30 & 70 & 30 \\
\hline B40 & 60 & 40 \\
\hline B50 & 50 & 50 \\
\hline B100 & 100 & 0 \\
\hline
\end{tabular}

\section{Analisis Sifat Kimia Biodiesel}

Parameter kimia yang diuji untuk menentukan kualitas dari biodiesel yang dihasilkan berfokus pada pengujian angka asam, nilai gliserol total serta nilai metil ester dari biodiesel. Standar pengujian untuk angka asam, gliserol total serta metil ester mengikuti standar pengujian yang telah teruji berdasarkan aturan dari forum biodiesel Indonesia [7].

Total angka asam dilakukan dengan mentitrasi sampel yang telah dilarutkan dalam pelarut organik (etanol:kloroform 1:1) dengan $\mathrm{KOH} 0.1 \mathrm{~N}$ dengan menggunakan indikator PP. Volume $\mathrm{KOH}$ yang digunakan untuk mngubah campuran menjadi warna merah muda dicatat sebagai volume $\mathrm{KOH}$. Adapun angka asam didapat berdasarkan persamaan (1).

$$
\text { TAN (Total Acid Number) }=\frac{56.1 \times \mathrm{N} \mathrm{KOH} \times \mathrm{V} \mathrm{KOH}}{\text { massa sample }}
$$

dimana $\mathrm{N} \mathrm{KOH}$ adalah normalitas larutan $\mathrm{KOH}$ dan $\mathrm{V}$ KOH adalah volume $\mathrm{KOH}$ yang digunakan.

Penentuan angka penyabunan dilakukan dengan menambahkan KOH alkoholik pada sampel biodiesel. Campuran tersebut dididihkan dengan menggunakan reflux yang dihubungkan pada kondensor dengan selama 1 jam. Setelah dingin dan terbentuk zat seperti jeli, bilas dengan akuades dan titrasi dengan $\mathrm{HCl}$ sampai warna merah jambu menjadi sirna. Angka penyabunan dihitung dengan menggunakan persamaan (2).

$$
\text { Angka penyabunan }\left(\mathrm{A}_{s}\right)=\frac{56,1(B-C) N}{m} \mathrm{mg} \mathrm{KOH} / \mathrm{g} \text { biodiesel }
$$

dengan:

$\mathrm{B}=$ volume $\mathrm{HCl}$ 0,5 $\mathrm{N}$ yang dihabiskan pada titrasi blanko, $\mathrm{ml}$. $\mathrm{C}=$ volume $\mathrm{HCl} 0,5 \mathrm{~N}$ yang dihabiskan pada titrasi contoh, $\mathrm{ml}$.

$\mathrm{N}=$ normalitas eksak larutan $\mathrm{HCl} 0,5 \mathrm{~N}$

$\mathrm{m}=$ massa contoh biodiesel ester alkil, $\mathrm{g}$.

Salah satu parameter yang harus ditentukan untuk menentukan kualitas dari biodiesel yang dihasilkan adalah penentuan kadar gliserol total. Sepuluh gram biodiesel dicampur dengan $100 \mathrm{ml}$ kloroform serta $50 \mathrm{ml}$ akuades. Campuran tersebut dikocok kuat selama $30-60$ detik. Campuran tersebut dibiarkan tenang, sampai lapisan organik $\left(\mathrm{CHCl}_{3}\right.$, kloroform ) dan lapisan air nya terpisah sempurna. Tiga ml dari lapisan air yang terbentuk dari campuran $\mathrm{CPO}-$ akuades - kloroform dicampur dengan asam periodat $\left(\mathrm{H}_{5} \mathrm{IO}_{6}\right)$ $2 \mathrm{ml}$ kedalam erlenmeyer. Campuran tersebut dibiarkan selama 30 menit sebelum ditambah $0.5 \mathrm{ml}$ larutan KI (Kalium Iodida). Campuran tersebut dititrasi dengan natrium tiosulfat $\left(\mathrm{Na}_{2} \mathrm{~S}_{2} \mathrm{O}_{3}\right)$ sampai warna coklat iodium hampir hilang. Setelah warna coklat memudar, campuran ditambahkan dengan kanji. Penambahan kanji mengakibatkan warna campuran berubah menjadi biru. Selanjutnya titrasi dilakukan sampai warna biru dari kanji dan iodin menjadi hilang. Adapun penentuan kadar gliserol total didapat dengan melakukan perhitungan dengan persamaan (3).

$$
\mathrm{G}_{\mathrm{ttl}}(\%-\mathrm{b})=\frac{2.302(B-C) N}{W}
$$

dengan:

$\mathrm{G}_{\mathrm{ttl}}=$ Gliserol total

$\mathrm{B}_{=}$volume $\mathrm{Na}_{2} \mathrm{~S}_{2} \mathrm{O}_{3}$ untuk blanko

$\mathrm{C}=$ volume $\mathrm{Na}_{2} \mathrm{~S}_{2} \mathrm{O}_{3}$ untuk sampel

$\mathrm{W}=$ massa sampel

Kadar ester dalam sampel biodiesel menjadi suatu parameter yang penting untuk diketahui, kadar ester menunjukan ke-efektifan proses esterifikasi yang terjadi. Untuk kadar ester didapatkan dari angka penyabunan, angka asam serta gliserol total, yang diformulasikan dengan persamaan (4) berikut:

$$
\operatorname{Kadar} \operatorname{ester}(\%-\mathrm{b})=\frac{100\left(A_{S}-A_{a}-4,57 G_{\mathrm{ttl}}\right)}{A_{S}}
$$

dengan:

$\mathrm{A}_{\mathrm{s}=}$ angka penyabunan

$\mathrm{A}_{\mathrm{a}=}$ angka Asam

$\mathrm{G}_{\mathrm{ttl}=\mathrm{gliserol} \text { total }}$

Seluruh teknik analisis sifat kimia biodiesel berdasarkan pada teknik analisis yang dikeluarkan oleh Forum Biodiesel Indonesia (FBI) [7].

\section{Analisis Sifat Fisika Biodiesel}

Sifat fisika yang diuji untuk sampel biodiesel serta campurannya adalah viskositas kinematik dan massa jenis dari sampel pada temperatur $40^{\circ} \mathrm{C}$ (sesuai pengujian SNI untuk viskositas biodiesel). Pengujian viskositas dilakukan dengan menggunakan Viskometer Ostwald dengan mengukur waktu yang diperlukan cairan uji untuk melewati batas yang telah ditentukan. Untuk penentuan viskositas kinematik dari cairan uji, maka selain dari waktu alir, data mengenai massa jenis dari cairan pada berbagai suhu perlu ditentukan. Massa jenis dari cairan uji pada berbagai suhu ditentukan dengan menggunakan metode piknometer [2].

Penentuan viskositas kinematik didapatkan dengan perhitungan (5) dan (6) sebagai berikut:

$$
\begin{aligned}
& v k=\frac{\eta \text { sample }}{\text { osample }} \\
& \eta \text { sample }=\frac{\text { tsample } x \text { ssample }}{\text { tair } x \text { pair }} \times \text { pair }
\end{aligned}
$$


dimana $\eta$ adalah viskositas dinamik $(\mathrm{g} / \mathrm{cm} \mathrm{s})$; vk= viskositas kinematik $\left(\mathrm{m}^{2} / \mathrm{s}\right)$; $\mathrm{t}=$ waktu alir (second); dan $\rho=$ massa jenis $(\mathrm{g} / \mathrm{ml})$.

\section{HASIL DAN PEMBAHASAN}

\section{A. Biodiesel dari $C P O$}

Hasil reaski esterifikasi dari asam lemak dan metanol adalah metil ester. Perubahan warna serta kekentalan dari CPO awal sampai menjadi hasil reaksi akhir setelah proses transesterifikasi menunjukan adanya perubahan struktur kimia dari CPO awal (berwarna kuning pekat kemerah-merahan) menjadi metil ester (biodiesel) yang berwarna kuning cerah seperti padaGambar 2 .

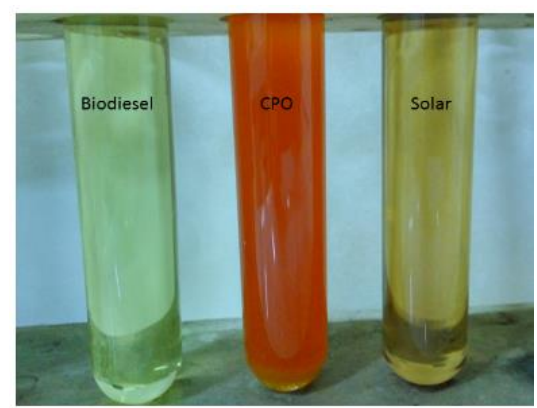

Gambar 2. Perbandingan Warna Biodiesel-CPO dan Solar

Banyaknya jumlah metil ester yang dihasilkan menunjukan efisiensi reaksi transesterifikasi. Berdasarkan standar mutu dari SNI, suatu biodiesel yang baik untuk bahan bakar harus lah memilki kadar metil ester minimal 96.5\% [2].Berdasarkan perhitungan yang dilakukan kadar metil ester dari biodiesel yang diproduksi dengan metode yang dilakukan memiliki kadar metil ester 99\%. Tingginya kadar metil ester yang dihasilkan menunjukan hampir semua trigliserida terkonversi menjadi metil ester. Hal tersebut juga menunjukan kondisi reaksi transesterifikasi berhasil dilakukan.

\section{B. Analisis Angka Asam Total dan Metil Ester dari Biodiesel}

Perubahan warna sampel hasil titrasi asam-basa untuk menghitung nilai angka asam ditunjukkan pada Gambar 3.
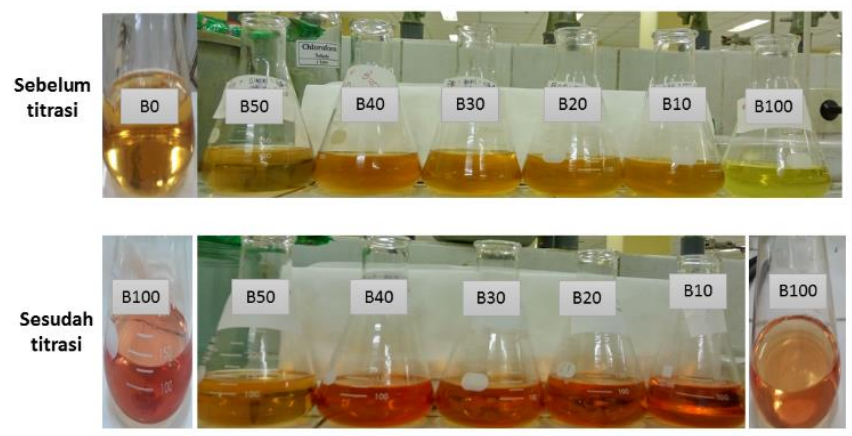

Gambar 3.Hasil Titrasi Sampel Biodiesel dan Campuran Biodiesel-Solar

Hasil reaksi esterifikasi, FFA dari CPO turun dari 5.6\% menjadi $1.36 \%$. Dengan demikian CPO hasil esterifikasi sudah memenuhi standar untuk dijadikan sumber bahan baku untuk pembuatan biodiesel.

Angka asam dari biodiesel yang dihasilkan hasil reaksi transesterifikasi dengan CPO dengan metanol memiliki nilai 0.531. Nilai tersebut masih di luar standar baku mutu yang ditetapkan oleh SNI (max 0.5). Masih belum terpenuhinya nilai angka asam total dari biodiesel yang dihasilkan dimungkinkan karena kadar FFA pada CPO awal masih tinggi. Proses esterifikasi yang dilakukan belum cukup efektif untuk mengurangi kadar asam total dalam biodiesel yang dihasilkan.

Campuran biodiesel-solar memiliki nilai angka asam lebih rendah dari biodiesel. Semakin besar komposisi solar pada campuran tersebut, semakin kecil nilai angka asam nya. Solar komersial memiliki angka asam sebesar 0.1. Penurunan nilai angka asam dari biodiesel, campuran biodiesel-solar serta solar sendiri ditunjukan padaGambar 4 .

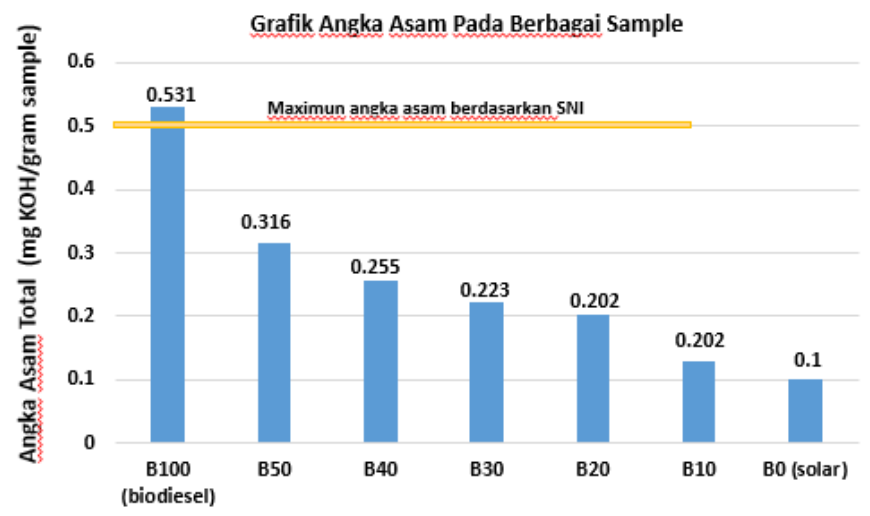

Gambar 4. Grafik Angka Asam Total (TAN) pada berbagai sampel

Berdasarkan Gambar 4,dapat disimpulkan nilai TAN dari semua sample campuran biodiesel dan solar sudah memenuhi standar baku mutu SNI untuk nilai TAN suatu biodiesel.

Nilai TAN yang besar dari suatu bahan bakar akan berpengaruh pada peningkatan laju korosi dari mesin kendaraan [11]. Angka asam dari biodiesel yang dihasilkan serta biodiesel campuran (dengan solar) akan berpengaruh pada seberapa kuat daya korosi dari mesin jika menggunakan bahan bakar tersebut.

\section{Viskositas Biodiesel}

Viskositas biodiesel harus memenuhi nilai SNI yang berkisar antara $2,3-6,0 \mathrm{~mm}^{2} / \mathrm{s}$ (cSt). Nilai viskositas yang terlalu tinggi dapat membuat atomisasi bahan bakar dan udara menjadi kurang baik yaitu berupa evaporasi yang lebih miskin sehingga pembakaran menjadi tidak sempurna [12].

Solar memiliki nilai viskositas $3,59 \mathrm{cSt}$, sedangkan biodiesel murni 4,35 cSt. Nilai viskositas ini didapatkan dengan data viskositas air sebagai acuannya. Viskositas campuran dari biodiesel dan solar ditunjukkan dalam Tabel II. dan Gambar 5.

Dapat dilihat pada Gambar 5 tersebut bahwa nilai viskositas hasil blending (pencampuran) biodiesel-solar berkisar antara 3,62 - 3,85 cSt (diagram batang berwarna biru). Nilai ini 
berada diatas ambang bawah SNI (2,3 cSt, garis berwarna merah pada grafik) dan berada di bawah ambang atas SNI (6,0 cSt, garis berwarna hijau pada grafik).

TABEL II. VISKOSITAS CAMPURAN BIODIESEL-SOLAR

\begin{tabular}{|c|c|}
\hline Sample & Viskositas (cSt) \\
\hline B100 (biodiesel) & 4,35 \\
\hline B50 & 3,85 \\
\hline B40 & 3,76 \\
\hline B30 & 3,72 \\
\hline B20 & 3,63 \\
\hline B10 & 3,62 \\
\hline B0 (solar) & 3,59 \\
\hline
\end{tabular}

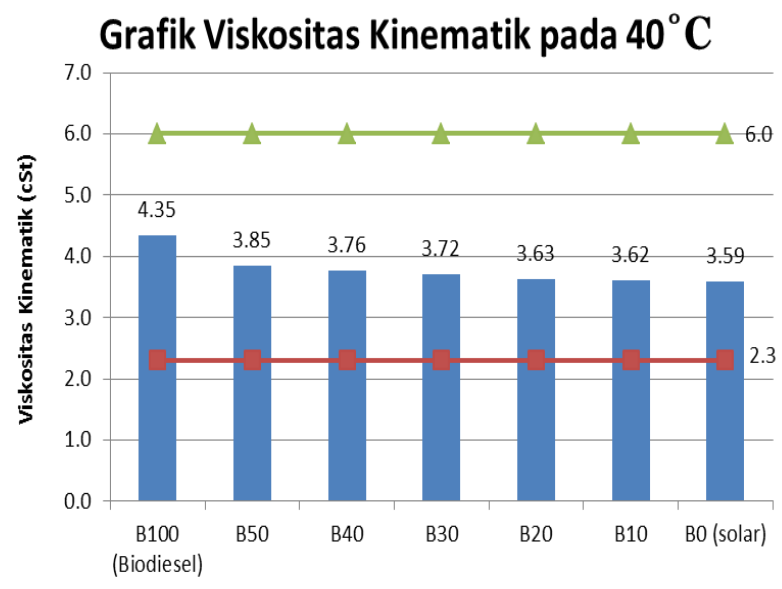

Gambar 5. Grafik Viskositas Campuran Biodiesel-Solar

\section{KESIMPULAN}

Ditinjau dari nilai angka asam, kadar metil ester, dan viskositasnya, biodiesel hasil blending dengan solar berbahan baku minyak kelapa sawit dari PT Smart Tbk memenuhi standar SNI dan dapat direkomendasikan sebagai bahan baku biodiesel nasional.

\section{UCAPAN TERIMA KASIH}

Ucapan terimakasih kami sampaikan pada Yayasan Institut Teknologi dan Sains Bandung atas dukungan dana serta pembinaan dalam penelitian ini. Ucapan terimakasih kami sampaikan juga pada Laboratorium Kimia Dasar Institut Teknologi Bandung atas ijin yang diberikan untuk pelaksanaan penelitian ini.

\section{DAFTAR PUSTAKA}

[1] Maritje Hutapea, "Kebijakan dan Program Pengembangan Bahan Bakar Nabati. Lokakarya Penggunaan Minyak Nabati Murni pada Motor Diesel dan Rekayasa Balik Motor Diesel”,2012,. Bandung. hal 3-28 .

[2] Badan Standardisasi Nasional (BSN), "Standard Nasional Indonesia “ Biodiesel".2006. SNI 04-7182-2006.

[3] Liu, Jiuxu, "Biodiesel Synthesis via Transesterification Reactionin Supercritical Methanol:a ) A Kinetic Study, b )Biodiesel Synthesis U sing Microalgae Oil", 2013, Biomedical and Chemical Engineering Theses. Paper 3 , page. 6-9.

[4] Demirbas, Ayhan, "Biodiesel from waste cooking oil via base-catalytic and supercritical methanol transesterification”, 2009, Energy Conversion and Management 50 page 923-927.

[5] Hayyan, A., Mjalli, F. S., Mirghani, M. E. S., Hashim, M. A., Hayyan, M., Alnashef, I. M., \& Al-zahrani, S. M,"Treatment of Acidic Palm Oil for Fatty Acid Methyl Esters Production”, 2012Chemical papers, 66(1), 39-46.

[6] Setyawati, Evi dan Edwar, Fatmir, "Teknologi Pengolahan Biodiesel dari Minyak Goreng Bekas dengan Teknik Mikrofiltrasi dan Transesterifikasi sebagai Alternatif Bahan Bakar Mesin Diesel”, 2012, Jurnal Riset Industri Vol. VI No. 2Hal. 1 17-127

[7] Forum Biodiesel Indonesia, "Analisis Biodiesel”. Lampiran I-IV.

[8] Che Man, Y.B, Aye, W.W, TAN, C.P. dan Abdulkarim, S.M, " Determination of Free Fatty Acids In Crude Palm Oil, Bleached Palm Oil and Bleached Deacidified Palm Oil by Fourier Transform Infrared Spectroscopy" 2009, Journal of Food Lipids. page. 475-483

[9] Che Man, Y.B., Haryati, T., Ghazali, H.M. dan Asbi, B.A., "Composition and Thermal Profile of Crude Palm Oiland Its Products", 1999, JAOCS, Vol. 76. page. 237-242

[10] Khalizani, Khalid dan Khalid Khalisanni, "Transesterification of Palm Oil for the Production of Biodiesel" 2011, American Journal of Applied Sciences 8 (8): 804-809

[11] Alptekin, E., \& Canakci, M.,"Determination of the density and the viscosities of biodiesel - diesel fuel blends", 2008, Renewable Energi, $33,2623-2630$

[12] Siti N Choiroh Shimmamah. "Karakterisasi Unjuk Kerja Mesin Diesel Generator Set Sistem Dual Fuel Biosiesel Minyak Sawit dan Syngas dengan Penambahan Preheating sebagai Pemanas Bahan Bakar". Januari 2017. Hal 1. 